\title{
AEROELASTICITY OF A GENERIC HYPERSONIC VEHICLE
}

\author{
B.J. Thuruthimattam, P.P. Friedmann, J.J. McNamara, and K.G. Powell ${ }^{\ddagger}$ \\ Department of Aerospace Engineering \\ University of Michigan \\ 3001 François-Xavier Bagnoud Bldg., 1320 Beal Ave \\ Ann Arbor, Michigan 48109-2140 \\ Ph: (734) 763-2354 Fax: (734) 763-0578 \\ email: peretzf@umich.edu
}

\begin{abstract}
This paper presents a treatment of the hypersonic aeroelastic problem, using both Euler and Navier-Stokes aerodynamics. The approach is based on the use of computational fluid dynamics coupled with structural finite element analysis. The structural motion is represented by a finite series of normal modes. Studies were carried out in the Mach number range of 2 to 15 , and for different altitudes between 5000 and 100,000 feet. The validation of the approach is carried out by considering the aeroelastic response analysis of a double wedge airfoil, using Euler, Navier-Stokes, and piston theory aerodynamics. Good comparison between piston theory and Euler aerodynamics is observed at all the operating points, and at higher Mach numbers, significant difference is observed between the viscous and inviscid aeroelastic response. This technique is then applied to the generic hypersonic vehicle, and the results presented.
\end{abstract}

\section{NOMENCLATURE}

a Parameter denoting the offset between the elastic axis and the origin

$a_{\infty} \quad$ Speed of sound

$b \quad$ Semi-chord

$c \quad$ Reference length, chord length of double wedge airfoil

$f(x) \quad$ Function describing airfoil surface

\footnotetext{
*Ph.D. Candidate

${ }^{\dagger}$ François-Xavier Bagnoud Professor of Aerospace Engineering

$\ddagger$ Arthur F. Thurnau Professor of Aerospace Engineering

${ }^{0}$ Copyright (C) 2002 by B. Thuruthimattam, P. Friedmann, J. McNamara, and K. Powell. Published by the American Institute of Aeronautics and Astronautics, Inc. by permission.
}

$h \quad$ Airfoil vertical displacement at Elastic Axis

$I_{\alpha} \quad$ Mass moment of inertia about the Elastic Axis

$K_{\alpha}, K_{h}$ Spring constants in pitch and plunge respectively; $K_{\alpha}=I_{\alpha} \omega_{\alpha}^{2}, K_{h}=m \omega_{h}^{2}$

$L \quad$ Lift per unit span

$M \quad$ free stream Mach number

$\mathbf{M}, \mathbf{K}$ Generalized mass and stiffness matrices of the structure

$m \quad$ Mass per unit span

$M_{E A} \quad$ Moment per unit span about the Elastic Axis

$P \quad$ Pressure; $P_{\infty}=\frac{a_{\infty}^{2} \rho}{\gamma}$

Q Generalized force vector for the structure

$Q_{i} \quad$ Generalized force corresponding to mode $i$

$q_{i} \quad$ Modal amplitude of mode $i$

$S \quad$ Surface area of the structure

$S_{\alpha} \quad$ Static mass moment of wing section about elastic axis

$T \quad$ Kinetic energy of the structure

$t \quad$ Time

$t_{h} \quad$ Airfoil half thickness

$U \quad$ Potential energy of the structure

$V \quad$ Free stream velocity

$v_{n} \quad$ Normal velocity of airfoil surface

$w \quad$ Displacement of structural surface

$x_{\alpha} \quad$ Parameter denoting the offset between the elastic axis and the center of gravity

$x, y, z \quad$ Spatial Coordinates

$Z(x, t)$ Position of airfoil surface

$\alpha \quad$ Airfoil pitch displacement about the Elastic Axis

$\gamma \quad$ Ratio of specific heats

$\mu \quad$ Air viscosity

$\rho \quad$ Air density

$\omega_{\alpha}, \omega_{h}$ Natural frequencies of uncoupled pitch 
and plunge motions

$\omega_{1}, \omega_{2}$ Natural frequencies of double wedged airfoil

$\Phi \quad$ Modal matrix

$\phi_{i} \quad$ mode shape for mode $i$

$\tau \quad$ Thickness ratio; $\tau=\frac{t_{h}}{b}$

()$,(\ddot{)} \quad$ First and second derivatives with respect to time

()$_{u},()_{l}$ Of the upper and lower surface, respectively

\section{INTRODUCTION AND PROBLEM STATEMENT}

In recent years, renewed activity in hypersonic flight research has been stimulated by the current need for a low cost, single-stage-to-orbit (SSTO) reusable launch vehicle (RLV) and the long term design goal of a single-stage-to-orbit, air-breathing flight vehicle. The X-33, an example of the former vehicle type, was a $1 / 2$ scale, fully functional technology demonstrator for the full scale VentureStar. Another ongoing hypersonic vehicle research program is the NASA Hyper-X experimental vehicle effort. Other activities are focused on the design of unmanned hypersonic vehicles that meet the needs of the US Air Force. This study addresses the characterization of the aeroelastic behavior of a generic version of such a vehicle throughout its entire flight envelope, which must be studied prior to the conceptual design of a hypersonic vehicle.

The vehicle is a blunt nosed lifting-body design that, due to stringent minimum-weight requirements, will possess a flexible fuselage, which provides most of the lift, as well as flexible canted fins. Furthermore, to meet the requirement of the flight profile, which can cover the Mach number range from 0 to 15 , the vehicle must be capable of withstanding severe aerodynamic heating. These factors combine to produce unusual aeroelastic problems which have not been explored extensively in the past. Furthermore, it is important to emphasize that testing using aeroelastically scaled wind tunnel models, a conventional practice in subsonic and supersonic flow, is not feasible in the hypersonic regime. Thus, the role of aeroelastic simulations is more important in this flight regime than in the other flight regimes.

Previous studies in this area can be combined in several groups. The first group consists of studies focusing on panel flutter, which is a localized aeroelastic problem representing a small portion of the skin on the surface of the hypersonic vehicle. Hypersonic panel flutter has been studied by a number of researchers, focusing on important effects such as aerodynamic heading [1], composite structure $[2,3]$, nonlinear structural model [4], and initial panel curvature [5]. A comprehensive review of this research can be found in a recent survey paper [6]. A fundamental question associated with these studies, is whether piston theory, which has been widely used in the Mach number range, $1.8<M<5.0$ is a suitable tool for modeling unsteady aerodynamic loads on the surface of a hypersonic vehicle. This was considered in Ref. [5], where the unsteady pressure coefficient on the surface of a typical panel, undergoing prescribed oscillations at frequencies representative of a typical panel in hypersonic flow, was computed using third-order piston theory, an exact solution of the nonlinear Euler equations, and a numerical solution of the unsteady Navier-Stokes equations. At a typical hypersonic Mach number $(M=10)$, results from the third-order piston theory are within $5 \%$ of the exact solution of the Euler equations. However, a difference of approximately $60 \%$ exists between the Euler solution and the solution based on the NavierStokes equations. This implies that the accurate representation of the unsteady aerodynamic loading, at certain flight conditions, will require the solution of the Navier-Stokes equations. Another implication of this statement is that the heat transfer problem may have to be coupled with the aeroelastic analysis of a hypersonic vehicle for certain portions of the flight envelope.

The second group of studies in this area was motivated by a focus on a previous hypersonic vehicle, namely the National Aerospace Plane (NASP). Representative studies in this category are Refs. [711]. However, most of these studies were focused on the transonic regime, because the NASA Langley researchers were interested in this region, which was considered to be critical, and their facilities (the Transonic Dynamics Wind Tunnel) were appropriate for testing vehicle behavior in this Mach number range.

The third group of studies is very limited since it is restricted to recent papers that deal with the newer hypersonic configurations such as the $\mathrm{X}$ 33 or the X-34. Ref. [12] considered the X-34 launch vehicle in free flight at $M=8.0$, and then reinterpreted these results at different flight conditions using dynamic pressure and altitude corrections. The aeroelastic instability of a generic hypersonic vehicle, resembling the X-33, was considered in Ref. [13]. It was found that at high hypersonic speeds and high altitudes, the hypersonic vehicle is stable, when piston theory is used to represent the aerodynamic loads. However, flutter boundaries were quite sensitive to the trim state and flexibility of the vehicle. 
In another reference [14], CFD-based flutter analysis is used for the aeroelastic analysis of the $\mathrm{X}-43$ configuration, by making use of order reduction of the aerodynamic degrees of freedom using system identification techniques. In this study, both the structure and the fluid were discretized using the finite element approach. It was observed that piston theory and ARMA Euler calculations predicted similar results.

From the studies on various hypersonic vehicles (Refs. [7,14-16]), one can identify a reasonable set of operating envelopes of each vehicle. By combining these envelopes, one can obtain a convenient graphical representation of operating envelopes shown in Fig. 2. Figure 2 was used to determine the operating points for this study, presented in Table 1.

The principal objectives of this study are to develop a physical understanding and effective computational techniques for the aeroelastic behavior of a generic hypersonic vehicle in trimmed level flight, operating throughout its entire flight envelope. This requires consideration of the three principal flight regimes of this vehicle, namely, subsonic, transonic and hypersonic, with an emphasis on the hypersonic regime. Thus, the specific objectives of this proposal are:

1. Develop an aeroelastic analysis capability for hypersonic vehicles in the Mach number range $0.5<M<15$, using computational aeroelasticity, i.e. computational fluid mechanics coupled with finite element structural analysis.

2. Validate the approach by applying it to the aeroelastic analysis of a double wedge airfoil.

3. Present trend-type results on a generic hypersonic vehicle.

Clearly, achieving these objectives will make an important contribution towards advancing the state of the art in hypersonic aeroelasticity, an important area of aeroelasticity which is still in its infancy.

\section{METHOD OF SOLUTION}

An overview of the method of solution of the computational aeroelasticity problem is shown in Fig. 3. The initial step consists of creating the vehicle geometry using a CAD software. Using this geometry, a mesh generator is used to create a structured mesh for the flow domain around the body, and an unstructured mesh is created for the structure using the same nodes on the vehicle surface as generated for the fluid mesh. The fluid mesh is next used to calculate the flow around the rigid body using a CFD solver, while the structural mesh is used to obtain the free vibration modes of the structure by finite element analysis. Then, using a node-matching procedure, the modal displacements at each structural node is matched to a corresponding node on the fluid mesh and the modal surface data for the aeroelastic solver is generated. Using the flow solution as an initial condition, and the modal information, an aeroelastic steady state is obtained. For the current geometry, this is not necessary due to its symmetry about the horizontal plane. Next, the structure is perturbed in one or more of its modes by an initial modal velocity condition, and the transient response of the structure is obtained. For the current study, the CFL3D code [17] is used to calculate both the flow around the rigid body and the aeroelastic response. This transient response is then analyzed to obtain its frequency and damping content, and from a set of such transient responses, the flutter boundary can be identified as either a function of altitude or Mach number.

\section{EULER/NAVIER-STOKES AEROELASTIC SOLVER}

The CFL3D code [17] is used to carry out the aeroelastic analyses of the generic hypersonic vehicle. It uses an implicit, finite-volume algorithm based on upwind-biased spatial differencing to solve the time-dependent Euler and Reynoldsaveraged Navier-Stokes equations. Multigrid and mesh-sequencing are available for convergence acceleration. The algorithm, which is based on a cellcentered scheme, uses upwind-differencing based on either flux-vector splitting or flux-difference splitting, and can sharply capture shock waves. For applications utilizing the thin-layer Navier-Stokes equations, different turbulence models are available. For cases involving a deforming mesh, an additional term accounting for the change in cell-volume is included in the time-discretization of the governing equations.

The aeroelastic approach underlying the CFL3D code is similar to that described in Refs. $[18,19]$. In this formulation, the equations are derived by assuming that the general motion $w(x, y, t)$ of the structure can be described by a separation of time and space variables in a finite modal series. The modes in this study were obtained from a finite element model of the vehicle. This modal series con- 
sists of the summation of the free vibration modes,

$$
w(x, y, t)=\sum_{i} q_{i}(t) \phi_{i}(x, y)
$$

The equations of motion are then formulated using Lagrange's equations,

$$
\frac{d}{d t}\left(\frac{\partial T}{\partial \dot{q}_{i}}\right)-\frac{\partial T}{\partial q_{i}}+\frac{\partial U}{\partial q_{i}}=Q_{i}, \quad i=1,2, \ldots
$$

The resulting set of equations of motion is

$$
\mathbf{M} \ddot{q}+\mathbf{K} q=\mathbf{Q}(\mathbf{q}, \dot{\mathbf{q}}, \ddot{\mathbf{q}}), \quad \mathbf{q}^{T}=\left[q_{1} q_{2} \ldots\right]
$$

where the elements of the generalized force vector are given by,

$$
Q_{i}=\frac{\rho V^{2}}{2} c^{2} \int_{S} \phi_{i} \frac{\Delta P d S}{\rho V^{2} / 2 c^{2}}
$$

From Eq. (3),

$$
\ddot{\mathbf{q}}=-\mathbf{M}^{-1} \mathbf{K q}+\mathbf{M}^{-1} \mathbf{Q}
$$

The aeroelastic equations are then written in terms of a linear state-space equation (using a state vector of the form $\left[\begin{array}{llllll}\ldots & \dot{q}_{i-1} & q_{i} & \dot{q}_{i} & q_{i+1} & \ldots\end{array}\right]^{T}$ ) such that a modified state-transition-matrix integrator can be used to march the coupled fluid-structural system forward in time. The fluid forces are coupled with the structural equations of motion through the generalized aerodynamic forces. To determine the flutter conditions at a given free-stream Mach number, aeroelastic transients are computed at several values of dynamic pressure to bracket the flutter point. The frequency and damping characteristics of the transient responses at each dynamic pressure are determined from a least squares curve fit, and the flutter dynamic pressure and frequency associated with this Mach number can be estimated by interpolation.

The code has previously been used to obtain the flutter boundary for the first AGARD standard aeroelastic configuration for dynamic response, Wing 445.6. The results of flutter calculations using Euler aerodynamics are given in [20] and those using Navier-Stokes aerodynamics are given in [21].

\section{COMPUTATIONAL MODEL OF THE GENERIC HYPERSONIC VEHICLE}

The mathematical model employed in this study is inspired by the $\mathrm{X}-33$ hypersonic vehicle. For the sake of simplicity, the mathematical model represents only the fuselage of a generic hypersonic vehicle (Fig. 1). In the current model, lifting surfaces such as fins are not considered as part of the geometry. The Euler and Navier-Stokes computations are performed on a $177 \times 41 \times 73$ grid with 177 points wrapped around the vehicle and its wake (97 points on the vehicle surface), 73 points distributed from side to side (41 points on the vehicle surface), and 41 points distributed radially outwards from the vehicle surface. A coarsened view of the computational domain is shown in Fig. 4. The computational domain extends one vehicular length to the upstream boundary and the upper and lower boundaries, two lengths to the downstream boundary, and one vehicular span off to the sides. For the Navier-Stokes simulations, the Spalart-Allmaras turbulence model was used, along with an adiabatic wall temperature condition.

\section{COMPUTATIONAL MODEL OF THE DOUBLE WEDGE AIRFOIL}

Validation of the CFL3D code for the hypersonic regime has never been undertaken. It was therefore essential to have reliable results for a fairly simple configuration for which aeroelastic stability and response results could be generated in an independent manner. The configuration selected for this purpose was the double wedge airfoil depicted in Figs. 5 and 6. Generating results for this configuration using Euler and Navier-Stokes unsteady aerodynamic loads, and comparing them with results obtained using an independently developed aeroelastic code based on third order piston theory, provides a reliable means for validating CFL3D in the hypersonic regime.

The Euler and Navier-Stokes computations are carried out using a $225 \times 65$ C-grid with 225 points around the wing and its wake (145 points wrapped around the airfoil itself), and 65 points extending radially outward from the airfoil surface. The computational domain extends one chordlength upstream and six chord lengths downstream, and one chord length to the upper and lower boundaries. For the Navier-Stokes simulations, the Spalart-Allmaras turbulence model was used, along with an adiabatic wall temperature condition. The double wedge airfoil and a portion of the surrounding computational grid are shown in Fig. 5.

HIGHER-ORDER PISTON THEORY MODEL OF THE DOUBLE WEDGE AIRFOIL

Piston theory is an inviscid unsteady aerodynamic method used extensively in hypersonic aeroelasticity, which predicts a point-function relationship between the local pressure on a lifting surface and the normal component of fluid velocity produced by the lifting surface motion $[22,23]$. The derivation 
utilizes the isentropic "simple wave" expression for the pressure on a piston,

$$
\frac{P(x, t)}{P_{\infty}}=\left(1+\frac{\gamma-1}{2} \frac{v_{n}}{a_{\infty}}\right)^{\frac{2 \gamma}{(\gamma-1)}}
$$

where

$$
v_{n}=\frac{\partial Z(x, t)}{\partial t}+V \frac{\partial Z(x, t)}{\partial x}
$$

The expression for piston theory is based on a binomial expansion of Eq. (6), where the order of the expansion is determined by the ratio of $\frac{v_{n}}{a_{\infty}}$. Reference [23] suggested a third order expansion, since it produced the smallest error of the various orders of expansion used when compared to the limiting values of pressure, namely the "simple wave" and "shock expansion" solutions. The third order expansion of Eq. (6) results in,

$$
\begin{aligned}
P(x, t)-P_{\infty}= & P_{\infty}\left[\gamma \frac{v_{n}}{a_{\infty}}+\frac{\gamma(\gamma+1)}{4}\left(\frac{v_{n}}{a_{\infty}}\right)^{2}\right. \\
& \left.+\frac{\gamma(\gamma+1)}{12}\left(\frac{v_{n}}{a_{\infty}}\right)^{3}\right]
\end{aligned}
$$

An aeroelastic analysis for a typical crosssection for a double wedge airfoil was developed using third-order piston theory. The geometry is illustrated in Fig. 6. The typical crosssection has the usual pitch and plunge degrees of freedom for which the equations of motion are obtained from Lagrange's equations.

$$
\begin{aligned}
m \ddot{h}+S_{\alpha} \ddot{\alpha}+K_{h} h & =-L(t) \\
S_{\alpha} \ddot{h}+I_{\alpha} \ddot{\alpha}+K_{\alpha} \alpha & =M_{E A}(t)
\end{aligned}
$$

The unsteady lift and moment in Eq. (9) were determined using third order piston theory. From Fig. 6, it is evident that for small displacements,

$$
Z(x, t)=-\{h(t)+(x-b a) \alpha(t)\}+f(x)
$$

and

$$
\begin{aligned}
& v_{n, u}=-\{\dot{h}+(x-b a) \dot{\alpha}\}+V\left\{-\alpha+\frac{\partial f(x)}{\partial x}\right\} \\
& v_{n, l}=\{\dot{h}+(x-b a) \dot{\alpha}\}-V\left\{-\alpha+\frac{\partial f(x)}{\partial x}\right\}
\end{aligned}
$$

where

$$
\begin{array}{llrl}
\frac{\partial f_{u}(x)}{\partial x}=\tau: & -b<x<0 \\
\frac{\partial f_{u}(x)}{\partial x}=-\tau: & 0<x<b \\
\frac{\partial f_{l}(x)}{\partial x}=-\tau: & -b<x<0 \\
\frac{\partial f_{l}(x)}{\partial x}=\tau: & 0<x<b
\end{array}
$$

From Eqs. (8), (11), and (12) the unsteady pressure distribution can be determined.

The unsteady lift and moment due to this pressure distribution can be determined by

$$
\begin{aligned}
L(t) & =\int_{-b}^{b}\left(P_{l}(x, t)-P_{u}(x, t)\right) d x \\
M_{E A}(t) & =-\int_{-b}^{b}(x-b a)\left(P_{l}(x, t)-P_{u}(x, t)\right) d x
\end{aligned}
$$

Thus, the unsteady lift is given by

$$
L(t)=L_{1}(t)+L_{2}(t)+L_{3}(t)
$$

where,

$$
\begin{aligned}
L_{1}(t)= & 4 P_{\infty} \gamma M b\left\{\frac{\dot{h}}{V}-b a \frac{\dot{\alpha}}{V}+\alpha\right\} \\
L_{2}(t)= & -P_{\infty} \gamma(\gamma+1) M^{2} b^{2} \tau\left(\frac{\dot{\alpha}}{V}\right) \\
L_{3}(t)= & \frac{1}{3} P_{\infty} \gamma(\gamma+1) M^{3} b\left\{\left(\frac{\dot{h}}{V}-b a \frac{\dot{\alpha}}{V}+\alpha\right)\right. \\
& \left.\left(\left(\frac{\dot{h}}{V}-b a \frac{\dot{\alpha}}{V}+\alpha\right)^{2}+3 \tau^{2}+\left(b \frac{\dot{\alpha}}{V}\right)^{2}\right)\right\}
\end{aligned}
$$

Note that $L_{1}(t), L_{2}(t)$, and $L_{3}(t)$ represent the first, second, and third order piston theory lift components respectively. Similarly, the unsteady moment is given by,

$$
M_{E A}(t)=M_{1}(t)+M_{2}(t)+M_{3}(t)
$$

where

$$
\begin{gathered}
M_{1}(t)=4 P_{\infty} \gamma M b^{2}\left\{a \frac{\dot{h}}{V}-\left(\frac{b}{3}+b a^{2}\right) \frac{\dot{\alpha}}{V}+a \alpha\right\} \\
M_{2}(t)=P_{\infty} \gamma(\gamma+1) M^{2} b^{2} \tau\left\{\frac{\dot{h}}{V}-2 b a \frac{\dot{\alpha}}{V}+\alpha\right\} \\
M_{3}(t)=-\frac{1}{3} P_{\infty} \gamma(\gamma+1) M^{3} b^{2}\left\{\frac{1}{5}\left(b \frac{\dot{\alpha}}{V}\right)^{3}\right. \\
-a\left(\frac{\dot{h}}{V}-b a \frac{\dot{\alpha}}{V}+\alpha\right)\left(\left(\frac{\dot{h}}{V}-b a \frac{\dot{\alpha}}{V}+\alpha\right)^{2}+3 \tau^{2}\right) \\
+b \frac{\dot{\alpha}}{V}\left(\left(\frac{\dot{h}}{V}-b a \frac{\dot{\alpha}}{V}+\alpha\right)^{2}+\tau^{2}\right. \\
\left.\left.\quad-b a \frac{\dot{\alpha}}{V}\left(\frac{\dot{h}}{V}-b a \frac{\dot{\alpha}}{V}+\alpha\right)\right)\right\}
\end{gathered}
$$

Note that $M_{1}(t), M_{2}(t)$, and $M_{3}(t)$ represent the first, second, and third order piston theory moment components respectively. 
For comparison with CFL3D, it is convienient to represent Eq. (9) in terms generalized coordinates and forces. Therefore, a normal mode transformation is used such that:

$$
\left\{\begin{array}{l}
h(t) \\
\alpha(t)
\end{array}\right\}=[\boldsymbol{\Phi}]\left\{\begin{array}{l}
q_{1}(t) \\
q_{2}(t)
\end{array}\right\}
$$

Substituting Eq. (18) into Eq. (9), and premultiplying by the transpose of the modal matrix yields

$$
\begin{aligned}
\left\{\begin{array}{c}
\ddot{q}_{1}(t) \\
\ddot{q}_{2}(t)
\end{array}\right\}= & {[\boldsymbol{\Phi}]^{T}\left\{\begin{array}{c}
-L(t) \\
M_{E A}(t)
\end{array}\right\} } \\
& -\left[\begin{array}{cc}
\omega_{1}^{2} & 0 \\
0 & \omega_{2}^{2}
\end{array}\right] \quad\left\{\begin{array}{l}
q_{1}(t) \\
q_{2}(t)
\end{array}\right\}
\end{aligned}
$$

for mass normalized modes.

Note that the modal amplitudes are coupled through the generalized forces. Equation (19) was solved using the subroutine ODE45 in MATLABC).

\section{RESULTS AND DISCUSSION}

Two sets of results are presented in this section. The first set of results represents a validation of CFL3D for the hypersonic regime. However, these results are also valuable for understanding hypersonic aeroelasticity. By comparing results for Euler, Navier-Stokes and piston theory over the operating envelope of a typical hypersonic vehicle, one can identify the regions where viscosity is important. The operating points for the vehicle are presented in Table 1, together with the Reynolds no. per foot $\left(\frac{\rho V}{\mu}\right)$ as common parameter applicable to both geometries. The second set of results depicts the aeroelastic response of a generic hypersonic vehicle using a computational aeroelasticity approach.

\section{AEROELASTIC BEHAVIOR OF THE DOUBLE WEDGE AIRFOIL}

The double wedge airfoil has a chord length $c$ of $2 \mathrm{~m}$., and a total thickness of $2.5 \%$ of chord, at midchord. The mass of the airfoil is $51.833 \mathrm{~kg} / \mathrm{m}$. The uncoupled pitch and plunge frequencies are 125 $\mathrm{rad} / \mathrm{sec}$ and $50 \mathrm{rad} / \mathrm{sec}$, respectively. The offset between the elastic axis and the midchord is $0.1 c$, and the offset between the elastic axis and the center of gravity is $0.05 c$.

Results for the operating conditions specified in Table 1 were obtained, and are shown in Figs. 711. For all operating conditions, the agreement between piston theory and Euler aerodynamics based solutions is quite good. Figures $7(M=2.0,5000$ feet) and $8(M=5.0,50,000$ feet $)$ indicate that for these flight conditions, the viscous effects are not very significant.

Figures 9-11 (100,000 feet) indicate that there is a significant difference between the results predicted from Navier-Stokes aerodynamics and the other two theories. At $M=7.0$ (Fig. 9), the Navier-Stokes solution indicates that the aerodynamic damping present is very small. Figure 10 shows that at $M=10.0$, the aeroelastic system with viscous effects experiences a slightly unstable response. There is no evidence of such an instability for the other theories. This is quite interesting since the addition of viscosity (or damping) seems to destabilize the system. At $M=15.0$, as shown in Fig. 11, the system is very clearly unstable. Piston theory indicates that at 100,000 feet, the airfoil section becomes unstable at $\mathrm{M}=34.0$.

As indicated in Ref. [24], the thick boundary layer in hypersonic flow can exert a major displacement effect on the inviscid flow outside the boundary layer, causing a given body shape to appear much thicker than it really is. Due to the extreme thickness of the boundary layer flow, the outer inviscid flow is greatly changed; the changes in the inviscid flow in turn feed back to affect the growth of the boundary layer. This major interaction between the boundary layer and the outer inviscid flow is called viscous interaction. Viscous interactions can have significant effects on the surface pressure distribution, in turn affecting the stability of hypersonic vehicles.

The pressure loading $\left(P-P_{\infty}\right)$ acting on the double wedge airfoil is shown in Fig. 12 for different operating points. As can be seen, for $M=2.0$ and $M=5.0$, the difference between Euler and NavierStokes aerodynamics is small. However, there is a significant difference between the pressure loading for the cases with $M=7.0$ and $M=15.0$. This trend is also displayed in Figs. 13 and 14, which show the flowfield around the double wedge airfoil, as described by the streamlines and contour plot of the pressure at points in the flow. The expansion of the flow on the rear half of the airfoil section at $M=2.0$ is similar for both cases. However, at $M=15.0$, the interaction between the thick boundary layer and the inviscid flow outside the boundary layer is quite significant, as shown in Fig. 14. Because of the boundary layer, there is no expansion of the flow on the rear half of the airfoil, which has a profound effect on the stability of the double wedge airfoil.

The very good comparison of the Euler and piston theory models indicates that the aeroelastic 
analysis technique has been validated. This technique will now be applied to aeroelastic analysis of the generic hypersonic vehicle.

\section{FREE VIBRATION MODES OF THE GENERIC HYPERSONIC VEHICLE}

The structural analysis of the vehicle is carried out using NASTRAN (C), using the finite element model shown in Fig. 1. The modes used for this analysis are restricted to the first five unrestrained modes (three predominantly bending and two predominantly torsional modes), shown in Figs. 15-19. The surface grid is the same as that used in the simulations using CFL3D. In order to prevent "breathing" modes, stiffening elements are inserted into the interior of the vehicle. The model has 7913 nodes, with 7680 bilinear plate elements on the surface, and an additional 728 elements used to represent the stiffeners. The material properties and thickness of the plate elements are chosen to enable approximate matching of the natural frequencies with those obtained from a finite element model of another representative generic hypersonic vehicle, obtained using the code ELAPS [25]. This is carried out by adjusting the thickness and density of the material to approximately match the frequencies of the vehicle given in Ref. [25].

\section{AEROELASTIC BEHAVIOR OF THE GENERIC HYPERSONIC VEHICLE}

At this point, only preliminary results are available for this geometry. Some typical results are shown in Fig. 20, for $M=7.0$, at 100,000 feet where only mode 1 has been excited with a modal velocity of 0.001 / sec. The limited results provided do not indicate a clearcut difference between the results from Euler and Navier-Stokes aerodynamics. This is not surprising since for a three-dimensional geometry, one can expect the "3D relieving effect" [26] where the flow can expand in both the vertical as well as the horizontal directions around the body. Figure 21 shows the stream traces of the flow around the upper left quarter of the vehicle. Thus, the shock wave and the viscous interaction for such a geometry would be much less pronounced as compared to a two-dimensional geometry with the same leading wedge angle. Correspondingly, the growth of the boundary layer would be much less pronounced, leading to a smaller difference in the aeroelastic response for viscous and inviscid flows, as compared to a corresponding $2 \mathrm{D}$ geometry.

\section{CONCLUDING REMARKS}

The results presented for the aeroelastic behavior of a double wedge airfoil in hypersonic flow corresponding to the operating envelope of a typical hypersonic vehicle were generated using a stand alone analysis using piston theory, as well as a computational aeroelasticity code obtained by combining CFL3D with a NASTRAN based finite element structural dynamic model. In the computational aeroelasticity code the unsteady aerodynamic loads were based on both Euler and Navier Stokes solvers. The good agreement between piston theory based results and the Euler solution in a large portion of the flight envelope validates the CFL3D code for the hypersonic flight regime, where it has not been used in the past. It is also interesting to note that substantial differences in prediction of aeroelastic stability behavior between Navier Stokes based and Euler solutions exist in certain portions of the flight envelope. These differences imply that viscous effects can be significant. Preliminary results based on a complete three dimensional generic hypersonic vehicle, seem to indicate that the difference between viscous and inviscid solutions on the vehicle are substantially smaller than on the double wedge airfoil. It appears that this reduction in the importance of the viscous terms can be partially attributed to three dimensional relief effects.

\section{ACKNOWLEDGEMENT}

The authors wish to express their gratitude to NASA Langley Research Center for the CFL3D code and thank Drs. R. Bartels and R. Biedron for their help in using this code. This research is funded by AFOSR under grant number F49620-01-1-0158 with Dr. D. Segalman as past Program Manager, and Dr. D. Mook as current program manager.

\section{REFERENCES}

[1] Xue, D.Y. and Mei, C., "Finite Element Two-Dimensional Panel Flutter at High Supersonic Speeds and Elevated Temperature," AIAA Paper No. 90-0982, Proc. 31st AIAA/ASME/ASCE/AHS/ASC Structures, Structural Dynamics and Materials Conference, 1990, pp. 1464-1475.

[2] Gray, E.G. and Mei, C., "Large-Amplitude Finite Element Flutter Analysis of Composite Panels in Hypersonic Flow," 
AIAA Paper No. 92-2130, Proc. 33rd AIAA/ASME/ASCE/AHS/ASC Structures, Structural Dynamics and Materials Conference, Dallas, TX, April 16-17 1992, pp. 492-512.

[3] Abbas, J.F. and Ibrahim,R.A., "Nonlinear Flutter of Orthotropic Composite Panel Under Aerodynamic Heating," AIAA J., Vol. 31, No. 8, No. 8, 1993, pp. 1478-1488.

[4] Bein, T., Friedmann, P., Zhong, X., and Nydick, I., "Hypersonic Flutter of a Curved Shallow Panel with Aerodynamic Heating," AIAA Paper No. 93-1318, Proc. 34th AIAA/ASME/ASCE/AHS/ASC Structures, Structural Dynamics and Materials Conference, La Jolla, CA, April 19-22 1993.

[5] Nydick, I., Friedmann, P.P., and Zhong, X., "Hypersonic Panel Flutter Studies on Curved Panels," AIAA Paper no. 95-1485, Proc. 36th AIAA/ASME/ASCE/AHS/ASC Structures, Structural Dynamics and Materials Conference, New Orleans, LA, April 1995, pp. 2995-3011.

[6] Mei, C., Abdel-Motagly, K., and Chen, R., "Review of Nonlinear Panel Flutter at Supersonic and Hypersonic Speeds," Applied Mechanics Reviews, 1998.

[7] Ricketts, R., Noll, T., Whitlow, W., and Huttsell,L., "An Overview of Aeroelasticity Studies for the National Aerospace Plane," AIAA Paper No. 93-1313, Proc. 34th AIAA/ASME/ASCE/AHS/ASC Structures, Structural Dynamics and Materials Conference, La Jolla, CA, April 19-22 1993, pp. 152 162.

[8] Spain, C. and Bullock, E., "A Flutter Investigation of All-Moveable NASP-Like Wings at Hypersonic Speeds," AIAA Paper No. 931315, Proc. 34th AIAA/ASME/ASCE/AHS/ $A S C$ Structures, Structural Dynamics and $M a-$ terials Conference, La Jolla, CA, April 19-22 1993.

[9] Scott, R.C. and Pototzky, A.S., "A Method of Predicting Quasi-Steady Aerodynamics for Flutter Analysis of High Speed Vehicles Using Steady CFD Calculations," AIAA Paper No. 93-1364, Proc. 34th AIAA/ASME/ASCE/AHS/ASC Structures, Structural Dynamics and Materials Conference, La Jolla, CA, April 19-22 1993, pp. 595-603.
[10] Spain, C., Zeiler, T.A., Gibbons, M.D., Soistmann, D.L., Pozefsky, P., DeJesus, R.O., and Brannon,C.P., "Aeroelastic Character of a National Aerospace Plane Demonstrator Concept," Proc. 34th AIAA/ASME/ASCE/AHS/ ASC Structures, Structural Dynamics and $M a-$ terials Conference, La Jolla, CA, April 19-22 1993, pp. 163-170.

[11] Heeg, J., Zeiler, T., Pototzky, A., Spain, C., and Engelund, W., "Aerothermoelastic Analysis of a NASP Demonstrator Model," AIAA Paper No. 93-1366, Proc. 34th AIAA/ASME/ASCE/AHS/ASC Structures, Structural Dynamics and Materials Conference, La Jolla, CA, April 19-22 1993, pp. 617-627.

[12] Blades, E., Ruth, M., and Fuhrman, D., "Aeroelastic Analysis of the X-34 Launch Vehicle," AIAA Paper No. 99-1352, Proc. 40th AIAA/ASME/ASCE/AHS/ ASC Structures, Structural Dynamics and Materials Conference, St. Louis, MO, 1999, pp. 1321-1331.

[13] Nydick, I. and Friedmann, P.P., "Aeroelastic Analysis of a Generic Hypersonic Vehicle," NASA/CP-1999-209136/PT2, Proc. CEAS/AIAA/ICASE/NASA Langley International Forum on Aeroelasticity and Structural Dynamics, Williamsburg, VA, June 22-25 1999, pp. $777-810$.

[14] Gupta, K.K., Voelker, L.S., Bach, C., Doyle, T., and Hahn, E., "CFD-Based Aeroelastic Analysis of the X-43 Hypersonic Flight Vehicle," AIAA Paper No. 2001-0712, 39th Aerospace Sciences Meeting \& Exhibit, 2001.

[15] Berry, S.A., Horvath, T.J., Hollis, B.R., Thompson, R.A., and Hamilton, H.H., "X-33 Hypersonic Boundary Layer Transition," AIAA 99-3560, 33rd AIAA Thermophysics Conference, Norfolk, VA, June 28 - July 11999.

[16] Riley, C.J., Kleb, W.L., and Alter, S.J., "Aeroheating Predictions for X-34 Using An InviscidBoundary Layer Method," AIAA 98-0880, 36th Aerospace Sciences Meeting \& Exhibit, Reno, NV, January 1998.

[17] Krist, S.L., Biedron, R.T., and Rumsey, C.L., "CFL3D User's Manual (Version 5.0)," NASA, TM 1998-208444, 1997.

[18] Robinson, B.A., Batina, J.T., and Yang, H.T., "Aeroelastic Analysis of Wings Using the Euler Equations with a Deforming Mesh," Journal of Aircraft, Vol. 28, November 1991, pp. 778-788. 
[19] Cunningham, H.J., Batina, J.T., and Bennett, R.M., "Modern Wing Flutter Analysis by Computational Fluid Dynamic Methods," Journal of Aircraft, Vol. 25, No. 10, No. 10, 1989, pp. $962-968$.

[20] Lee-Rausch, E.M. and Batina, J.T., "Wing Flutter Boundary Prediction Using Unsteady Euler Aerodynamic Method," AIAA Paper No. 93-1422, Proceedings of the 34th AIAA/ASME/ASCE/AHS Structures, Structural Dynamics and Materials Conference, 1993, pp. 1019-1029.

[21] Lee-Rausch, E.M. and Batina, J.T., "Calculation of AGARD Wing 445.6 Flutter Using Navier-Stokes Aerodynamics," AIAA Paper No. 93-3476, Proceedings of the AIAA 11th Applied Aerodynamics Conference, Hampton, VA, August 9-11 1993.

[22] Ashley, H. and Zartarian, G., "Piston Theory - A New Aerodynamic Tool for the Aeroelastician," Journal of the Aeronautical Sciences, Vol. 23, No. 12, No. 12, 1956, pp. 1109-1118.

[23] Lighthill, M.J., "Oscillating Airfoils at High Mach Numbers," Journal of the Aeronautical Sciences, Vol. 20, No. 6, June 1953.

[24] Anderson, J.D., Hypersonic and High Temperature Gas Dynamics, New York, McGraw-Hill, 1989.

[25] Nydick, I., "Studies in Hypersonic Aeroelasticity," Ph.D. Dissertation, University of California, Los Angeles, 2000.

[26] Anderson, J.D., Modern Compressible Flow, with Historical Perspective, New York, McGraw-Hill, 1990.

Table 1: Operating points for present study.

\begin{tabular}{|c|c|c|}
\hline Altitude (feet) & $M$ & $\begin{array}{c}\text { Reynolds no. } \\
\text { per foot }\left(\frac{\rho V}{\mu}\right)\end{array}$ \\
\hline 5000 & 2 & $1.2 \times 10^{7}$ \\
50,000 & 5 & $3.1 \times 10^{7}$ \\
100,000 & 7 & $7.6 \times 10^{5}$ \\
100,000 & 10 & $1.1 \times 10^{6}$ \\
100,100 & 15 & $1.6 \times 10^{6}$ \\
\hline
\end{tabular}

Note: chord-length of airfoil section : 6.66 feet, length of generic hypersonic vehicle : 76.2 feet

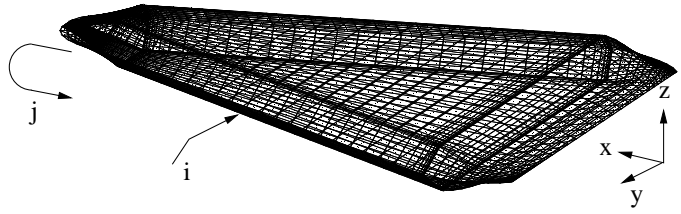

Figure 1: Discrete structural model of generic hypersonic vehicle, (internal stiffeners not shown).

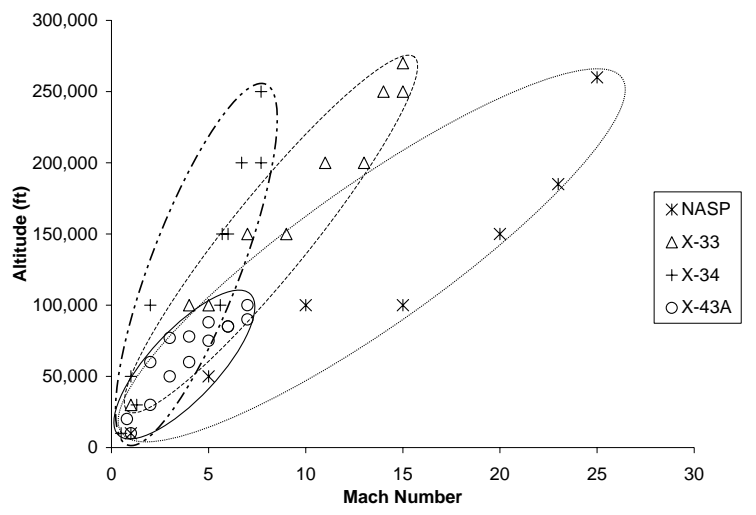

Figure 2: Operating envelopes for several modern hypersonic vehicles.

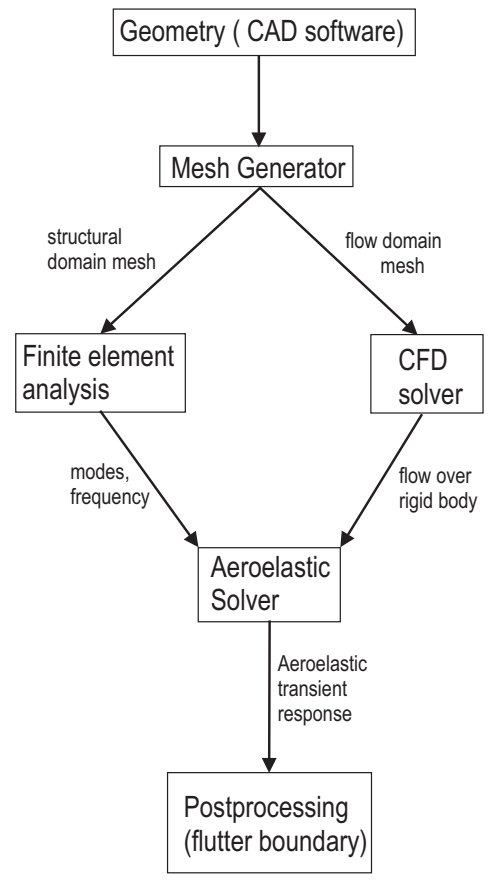

Figure 3: A flow diagram of the computational aeroelastic solution procedure. 


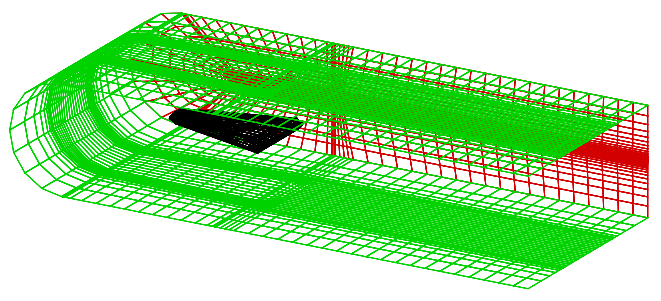

Figure 4: A representative view of the computational domain.

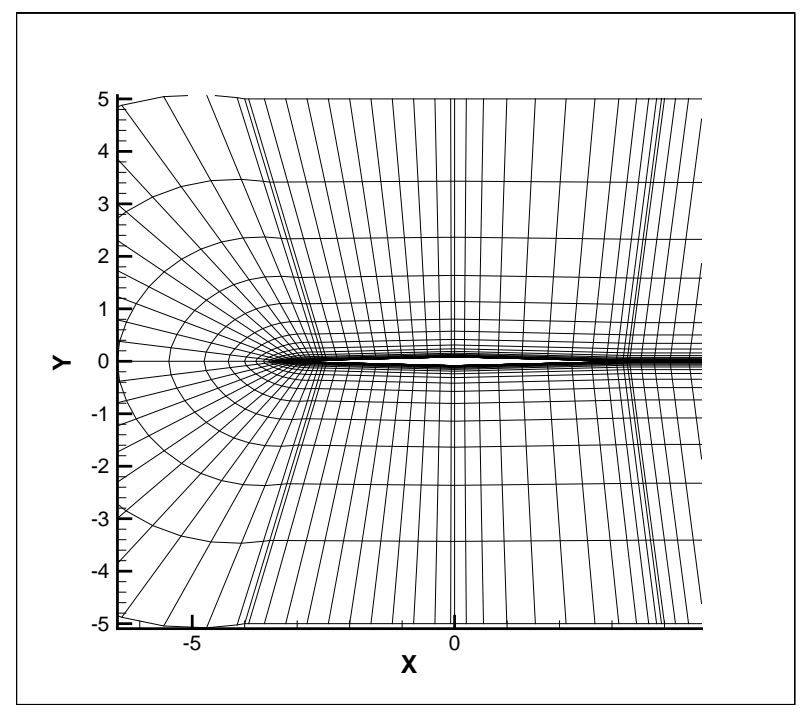

Figure 5: Diamond shaped airfoil section, and surrounding grid, to scale.

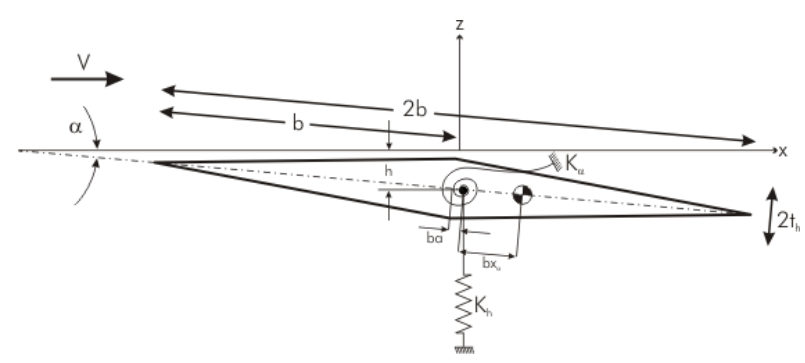

Figure 6: Two degree-of-freedom typical airfoil geometry.
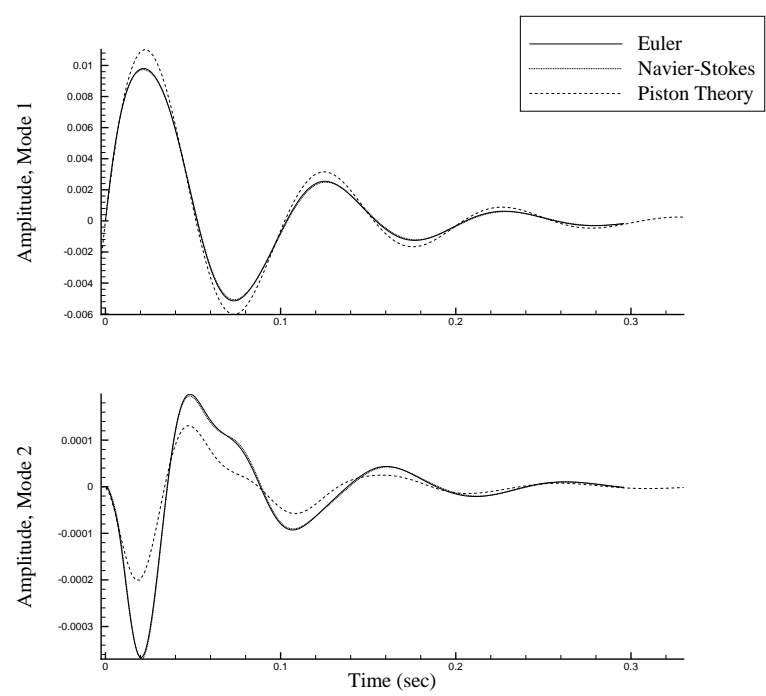

Figure 7: Aeroelastic results for the diamond-shaped airfoil, at $M=2.0$ and an altitude of 5000 feet.
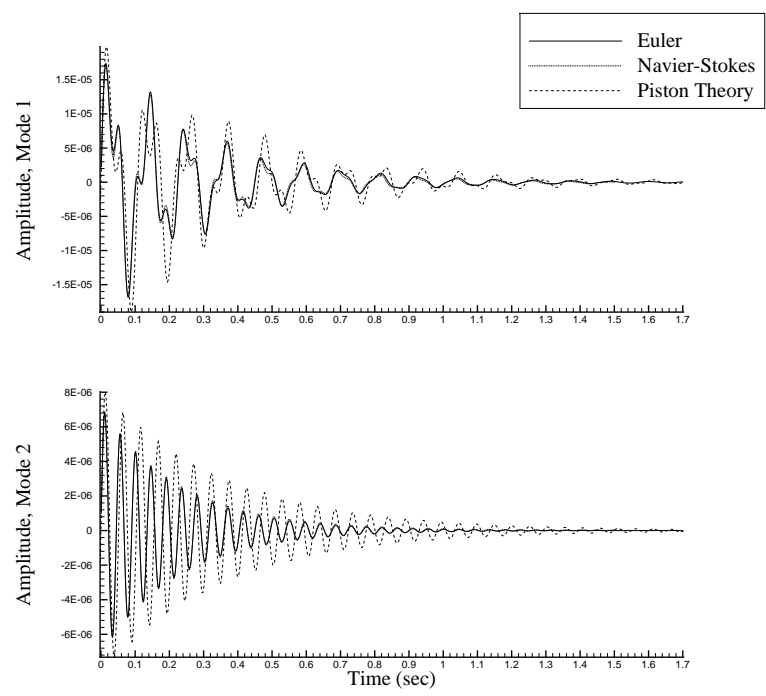

Figure 8: Aeroelastic results for the diamond-shaped airfoil, at $M=5.0$ and an altitude of 50,000 feet. 


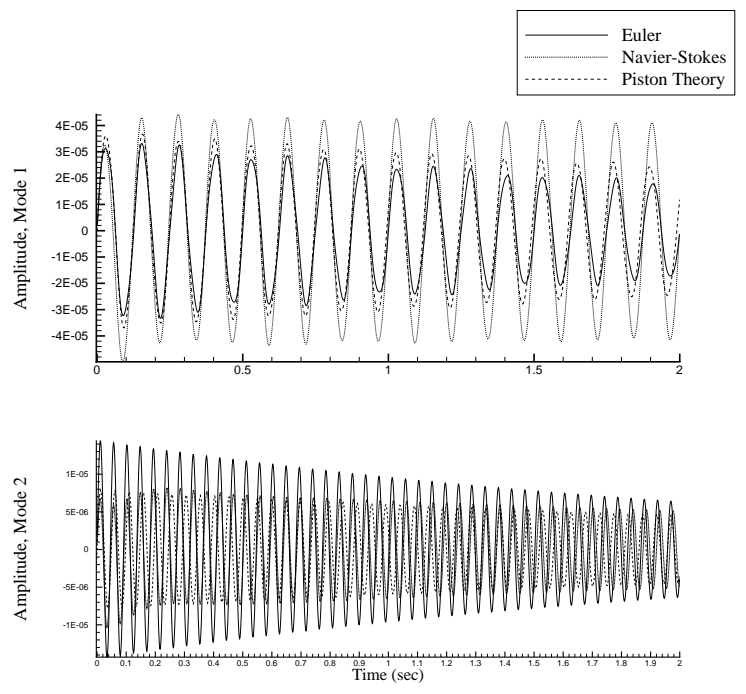

Figure 9: Aeroelastic results for the diamond-shaped airfoil, at $M=7.0$ and an altitude of 100,000 feet.

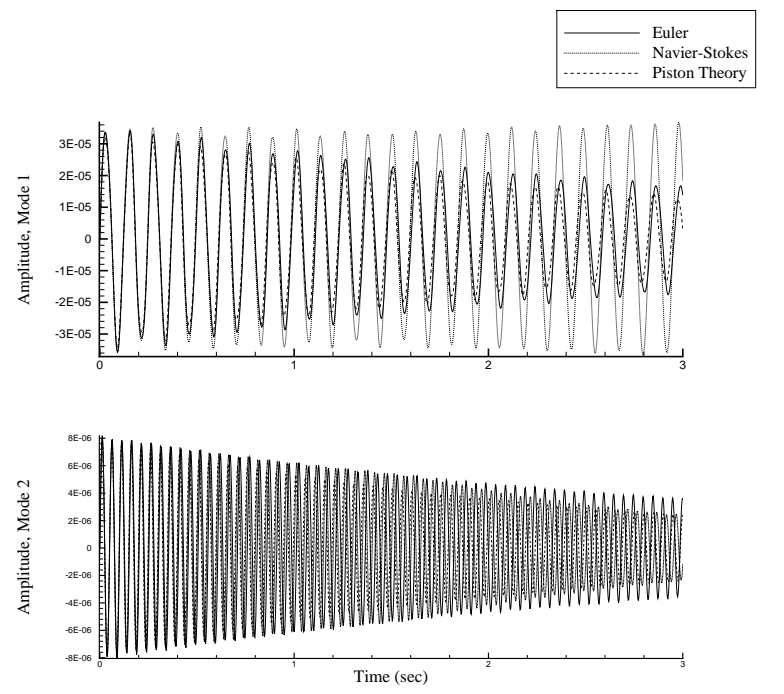

Figure 10: Aeroelastic results for the diamondshaped airfoil, at $M=10.0$ and an altitude of 100,000 feet.
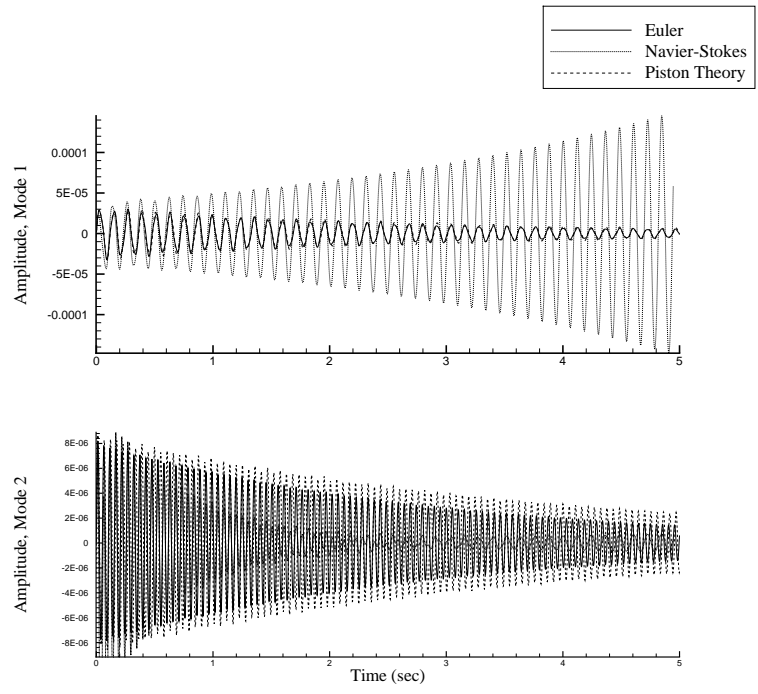

Figure 11: Aeroelastic results for the diamondshaped airfoil, at $M=15.0$ and an altitude of 100,000 feet.
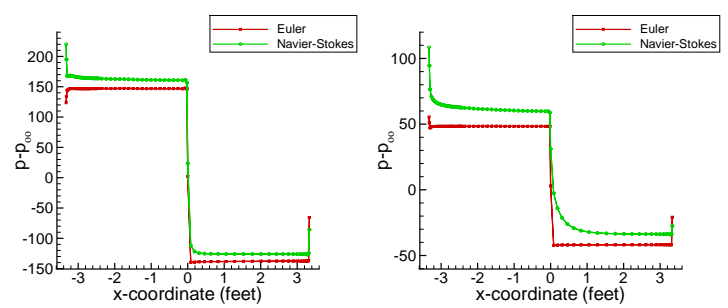

(a) $M=2.0,5000$ feet

(b) $M=5.0, \quad 50,000$
feet
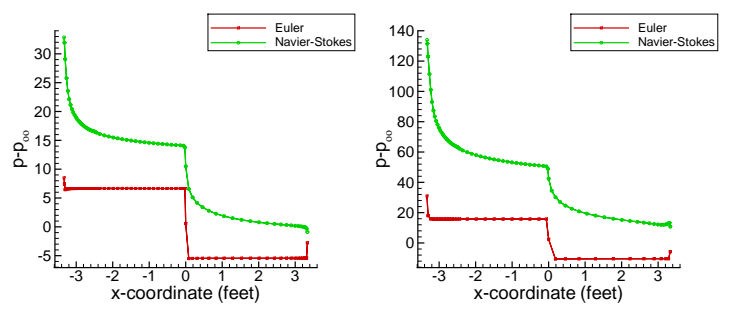

$\begin{array}{ll}\text { (c) } M=7.0,100,000 & \text { (d) } M=15.0,100,000 \\ \text { feet } & \text { feet }\end{array}$

Figure 12: Pressure distributions $\left(p-p_{\infty}\right)$ at different operating conditions, 


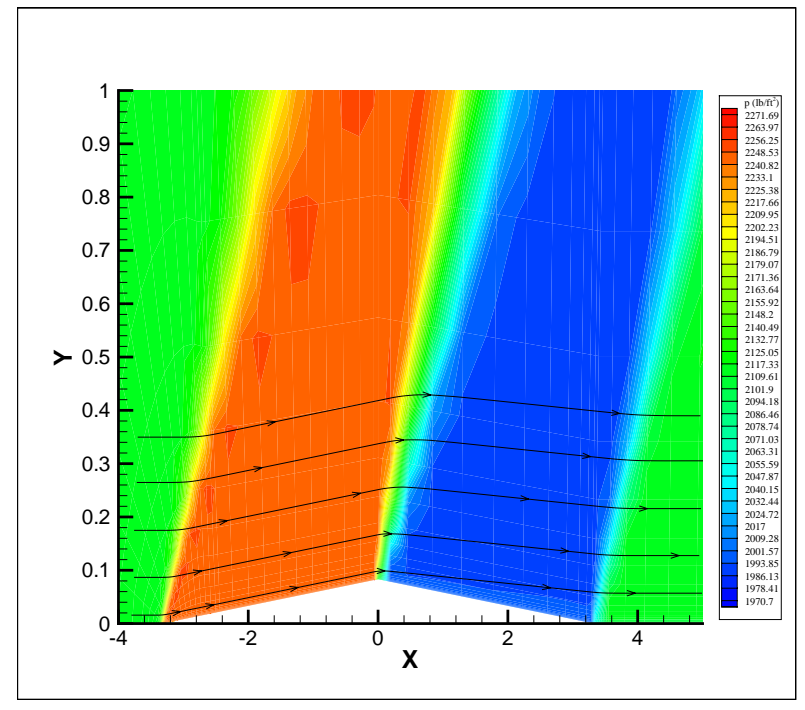

(a) Using Euler aerodynamics.

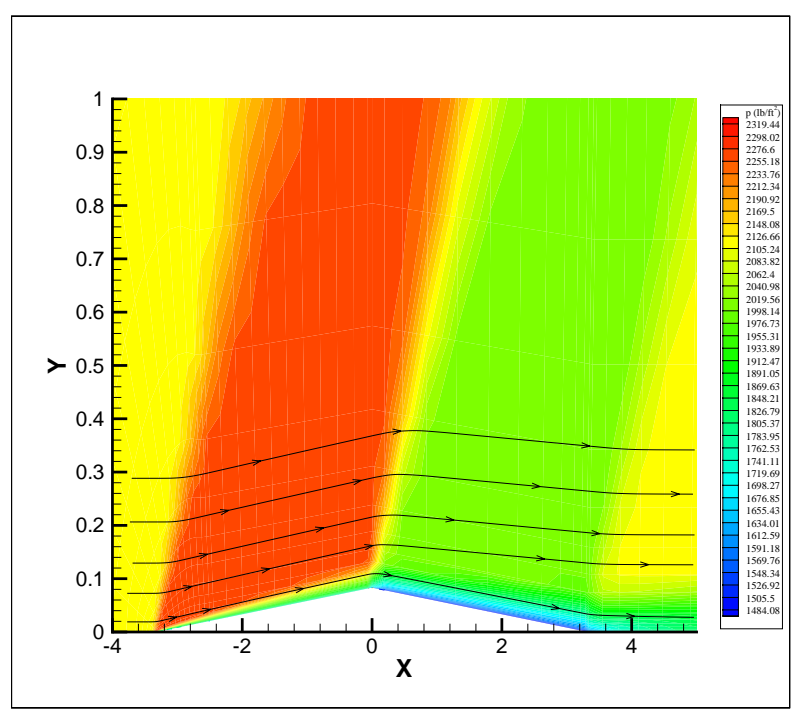

(b) Using Navier-Stokes aerodynamics

Figure 13: Flow patterns around the diamondshaped airfoil, $M=2.0,5000$ feet.

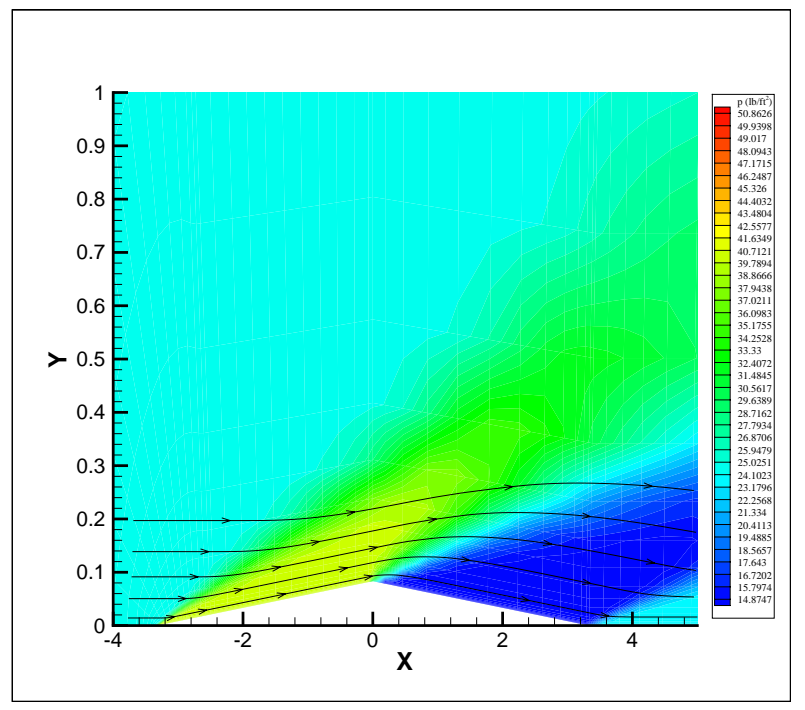

(a) Using Euler aerodynamics.

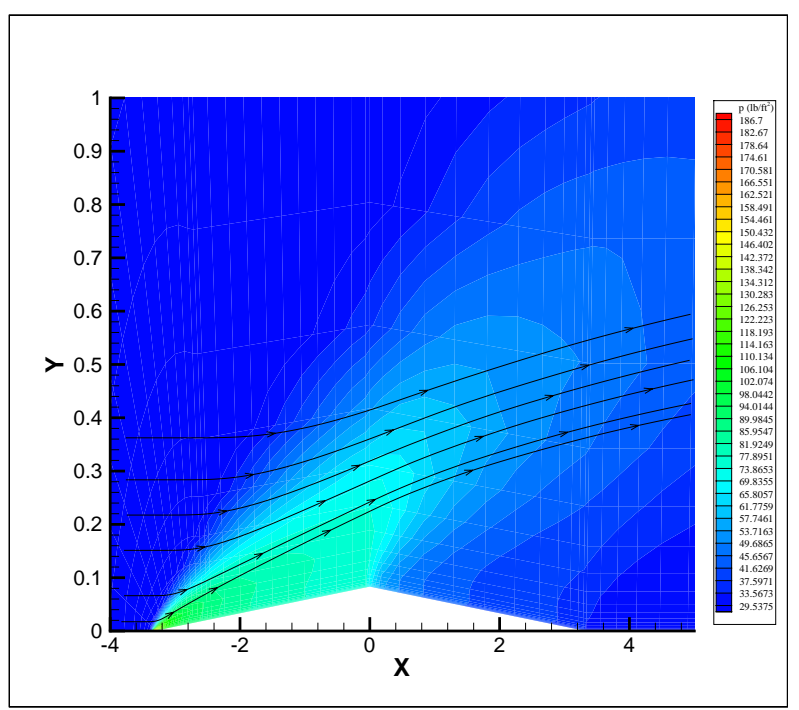

(b) Using Navier-Stokes aerodynamics

Figure 14: Flow patterns around the diamondshaped airfoil, $M=15.0,100,000$ feet. 


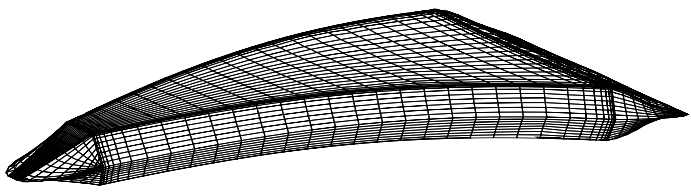

Figure 15: 1st bending mode of generic hypersonic vehicle, $10.48 \mathrm{~Hz}$

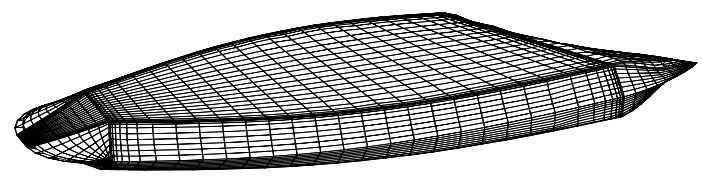

(a) Isometric view

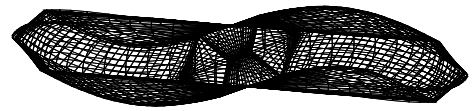

(b) Frontal view

Figure 16: 1st torsional mode of generic hypersonic vehicle, $10.81 \mathrm{~Hz}$.

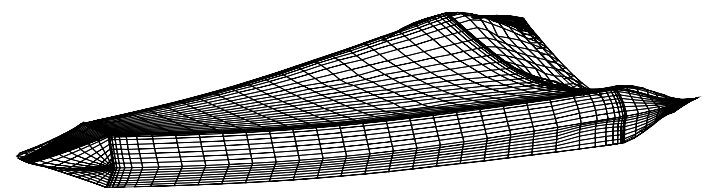

Figure 17: 2nd bending mode of generic hypersonic vehicle, $18.71 \mathrm{~Hz}$

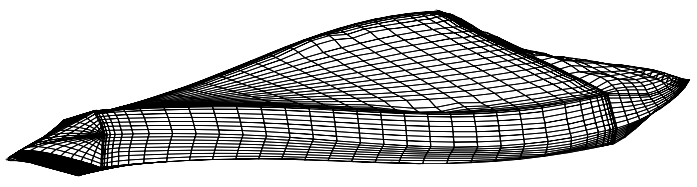

(a) Isometric view

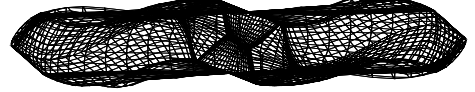

(b) Frontal view

Figure 18: 2nd torsional mode of generic hypersonic vehicle, $20.39 \mathrm{~Hz}$.

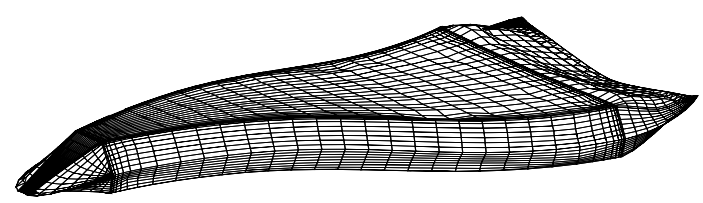

Figure 19: 3rd bending mode of generic hypersonic vehicle, $24.26 \mathrm{~Hz}$ 


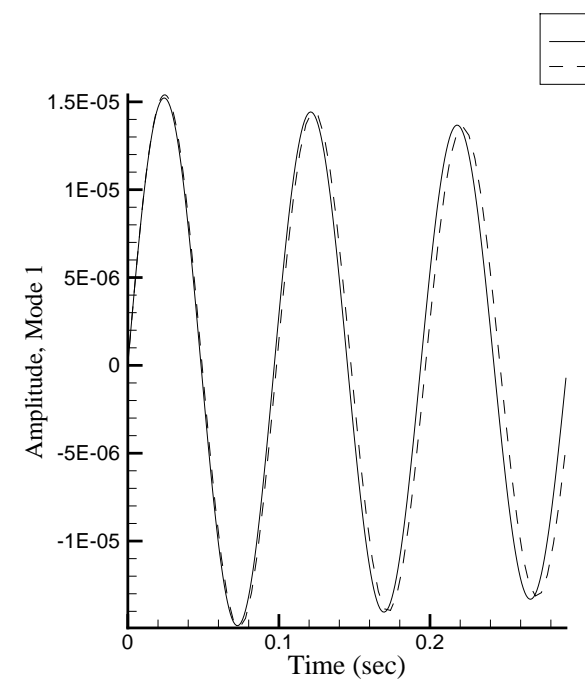

(a) Mode 1 .
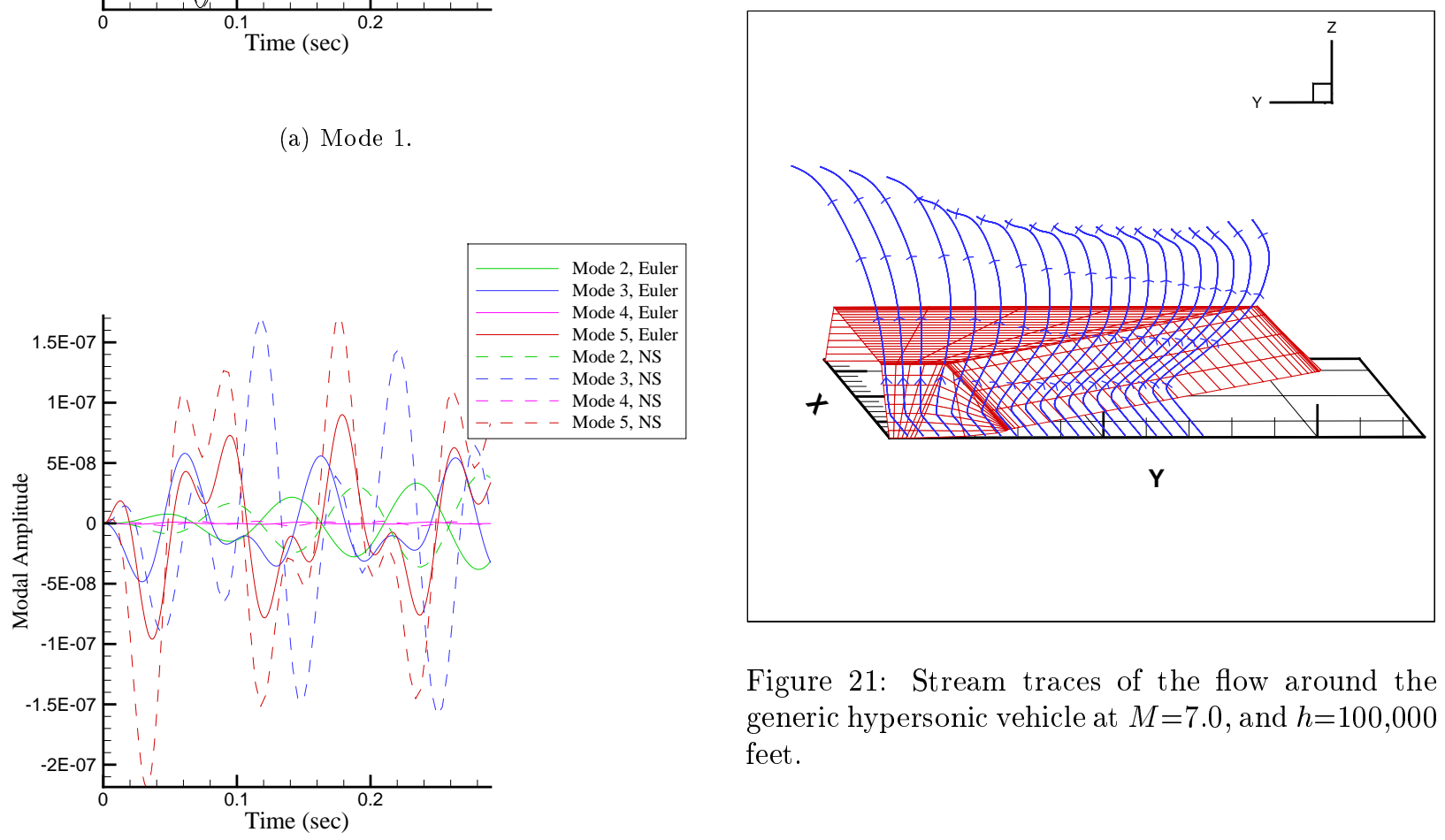

Figure 21: Stream traces of the flow around the generic hypersonic vehicle at $M=7.0$, and $h=100,000$ feet.

(b) Modes 2-5.

Figure 20: Aeroelastic results for the generic hypersonic vehicle, at $M=7.0$ and an altitude of 100,000 feet. 